\title{
INFORMAÇÃO, CIENCIA E TECNOLOGIA NA SOCIEDADE DA INFORMAÇÃO NO CONTEXTO DA WEB 3.0: UMA ANÁLISE A PARTIR DE TRES QUESTÕES
}

\author{
Information, science and technology in information \\ society in the context of web 3.0: an analysis starting from \\ three questions
}

\section{Francisco Carlos Paletta}

Doutor em Tecnologia Nuclear (USP). Docente Pesquisador (USP).

\section{Bárbara Pelissaro}

Mestre em Literatura e Cultura Russa(USP). Coordenadora de Revisão da Trip Editora.

\begin{abstract}
RESUMO: Discute os desafios de ordem informacional presentes na Sociedade da Informação no contexto da Web 3.0. Caracteriza tal sociedade e conceitua a Web 3.0, de modo a permitir uma abordagem das principais dificuldades e dos principais problemas enfrentados neste quadro com foco em três pilares: a tecnologia, o Estado e o poder. Objetiva refletir sobre o papel crucial da informação na Sociedade do Conhecimento e sua transformação no contexto da Web 3.0, baseando-se na revisão bibliográfica de artigos científicos e acadêmicos que auxiliam na compreensão desse advento e no processo de entendimento do papel do sujeito frente à tecnologia e às mudanças econômicas e sociais no cenário contemporâneo. Verifica-se que as tecnologias da informação, em especial a internet, vêm promovendo mudanças significativas na sociedade, alterando seu comportamento, demandas e necessidades, tendo sido incorporada de maneira natural pelos usuários, com atores e linguagens específicas para compor sua estruturação, porém, problemas de ordem social não garantem a inclusão total dos cidadãos, criando um abismo de oportunidades, com ocorrência desleal em um jogo de poder.
\end{abstract}

PALAVRAS-CHAVE: Sociedade da Informação. Web 3.0. Informação. Conhecimento. Tecnologia.

ABSTRACT: This study discusses the challenges regarding information in the Information Society in the context of Web 3.0. Features such society and conceptualizes Web 3.0 in order to allow an approach of the main difficulties and the main problems faced in this context, focusing on three pillars: technology, State 
and power. Aims to reflect on information's crucial role in the Knowledge Society and its transformation in the context of Web 3.0, based on bibliographic reviews of scientific and academic papers that help understanding of such a novelty and also on the process of understanding the role of the subject towards technology and the social and economic changes in a contemporary context. It is found that information technologies, especially the internet, have been promoting significant changes in society, changing their behavior, demands and needs, having been naturally incorporated by users, with players and specific languages in order to build its structure. However, an array of social issues does not guarantee full integration and inclusion of citizens, creating an abyss of opportunities, which leads up to a disloyal game of power.

KEYWORDS: Information Society. Web 3.0. Information. Knowledge. Technology..

\section{Introdução}

A tecnologia está cada vez mais presente nas atividades profissionais e cotidianas, passando de meras ferramentas a verdadeiras mediadoras do acesso ao conhecimento. $\mathrm{O}$ advento da internet e seu desenvolvimento constante têm deixado cada vez mais latente a preocupação com a manipulação dos dados, a disseminação da informação e o rumo do conhecimento. A qualidade de interação com os meios digitais, a capacidade de lidar com eles e a confiabilidade de seu conteúdo são pontos que permeiam a construção do diálogo da atual sociedade com o crescimento e a potencialização do conhecimento, assim como acirra a discussão sobre os aspectos econômicos e sociais transformados por esse meio.

A evolução tecnológica com a Web 3.0 vê que o processo de busca e recuperação dos recursos informacionais devem ser facilitados com ferramentas tecnológicas e uma melhor representação da informação, construindo uma rede de conhecimentos interligados ao mesmo tempo em que respeita o tipo de usuário ou comunidade presente em cada ambiente. As tecnologias contribuíram para modificar a vida social, de modo que os ambientes digitais em que há interação de usuários permite que esses acessem, manipulem e transformem a informação, criando um mundo próprio e um campo de reflexão, uma vez que é composto de empresas privadas, órgão públicos, cidadãos comuns e comunidades científica e acadêmica. Surge então um paradigma que tem como aspecto central a "penetrabilidade das tecnologias da informação na vida das sociedades humanas, moldando comportamentos e tendências em determinados contextos históricos" (NICOLAU; SANTOS, 2012, 
p. 03).

Nesse quadro, torna-se necessário refletir sobre as demandas públicas e as questões sociais de inclusão e acesso à informação, assim como a posição do Estado frente a essa demanda, uma vez que há produção descontrolada de informações que são disponibilizadas constantemente, interferindo na confiabilidade da informação e na vigilância do usuário, e porque tornou-se necessário para as empresas privadas estarem presentes nesse contexto, pois encontraram nesse ambiente um meio de geração de lucros, interferindo em padrões de ética e na competitividade do mercado.

\section{Uma questão de tecnologia}

O termo Web Semântica surge pela primeira vez em 2001, no periódico Scientific American, porém, a concepção da Web 3.0 foi esclarecida apenas em 2009. ${ }^{1}$ Desde a década de 1990, essa Web já estava sendo desenvolvida, num processo que apontava um caminho natural de agregação de significado e informação à ela por meio

É necessário destacar que Alves e Santos (2009) estabelecem uma diferença entreWeb 3.0 eWeb Semântica, sendo a primeira uma denominação para o período de evolução da Web (antecedida pela 1.0 e 2.0) marcada pela criação de ambientes informacionais especializados, e a segunda uma denominação para a estrutura tecnológica criada para estabelecer um nível semântico entre os dados. Neste artigo, utiliza-se ambas como sinônimos, uma vez que se entende e se reconhece uma delimitação não muito clara entre a utilização dos termos. de três ferramentas: as ontologias, os bancos de dados e a linguagem de descrição. A Ciência da Informação e as tecnologias vêm para permitir uma melhor integração do vocabulário controlado à estrutura da Web, sendo necessário o desenvolvimento de ontologias e sistemas que auxiliem nessa integração, criando assim uma tecnologia de infraestrutura de tecnologia.

A reunião de usuários organizados em grupos de trabalhos que discutiam o crescimento da Web culminou no desenvolvimento de tecnologias, como linguagens de marcação, que propiciaram o desenvolvimento de portais, sites e blogs. As ferramentas desses recursos possibilitavam a marcação de metadados feitas aleatoriamente por usuários, gerando a necessidade de organização desse ambiente digital. É de extrema importância a organização dos dados e sua padronização, assim como a relação dos dados disponibilizados, numa espécie de conjunto de dados interrelacionados (Linked Data) passíveis de publicar dados estruturados na Web e relacioná-los, vinculá-los de modo a se tornarem mais úteis. A Web 3.0 está em fase de desenvolvimento e depende de mecanismos e agentes que a torne 
mais organizada e a informação disponível mais facilmente encontrada, de uma plataforma e estabelecimento de critérios de relevância em sua padronização.

De acordo com Alves e Santos (2009), a proposta da Web Semântica é disponibilizar recursos informacionauis mais bem estruturados e representados, formando uma rede de informações conectadas que por meio de ferramentas tecnológicas.

A Web Semântica é uma Web de Dados - de dados, títulos, identificações, propriedades e quaisquer outros dados que se possa produzir. As tecnologias da Web Semântica [...] fornecem um ambiente onde uma aplicação pode consultar esses dados e/ou fazer inferências usando vocabulários controlados. (MUCHERONI, PALETTA, 2014 p.80).

A Web 3.0 - ou Web Semântica ou Web inteligente - é capaz de adicionar maior significado aos recursos informacionais disponibilizados, combinando técnicas de inteligência artificial na realização de tarefas relacionadas ao entendimento semântico da informação por meio do desenvolvimento de ferramentas de busca semântica e base de dados semântica. As máquinas não são aptas a interpretar palavras dentro de um contexto, pois trabalham com processamento lógico. A proposta de estruturar e contextualizar semanticamente os dados visa, por uma rede de informações conectadas, diminuir os problemas de recuperação; para isso, é necessário que haja uma nova arquitetura da Web, em que todas as ferramentas trabalhem em conjunto para garantirem seu funcionamento, estando categorizadas nas seguintes camadas: característica internacional, camada sintática, camada de dados, camada de ontologia, camada lógica, camada de prova e camada de validação, estando uso de padrões de metadadosimplícito na camada sintática e na camada de dados (MOURA, 2002 apud ALVES; SANTOS, 2009).

O compartilhamento de um espaço de informação semântica eficaz só é construído com o gerenciamento de conteúdos e a integração de informações de diferentes fontes, de modo a disponibilizar rapidamente toda riqueza de informação em formato digital com ferramentas de busca otimizadas e aproveitando toda sorte de combinação de dados, textos ou documentos disponíveis. O crescimento contínuo de páginas da internet e a complexidade das pesquisas de busca devido à infinidade de informações disponíveis, exigem uma organização que torne a experiência do usuário mais rápida e menos frustrante, uma vez que espera respostas mais precisas 
e inteligentes

\section{Uma questão de Estado}

Toda sociedade é composta de atores sociais que atuam conforme suas responsabilidades e de acordo com o que se espera de seu papel. A Sociedade da Informação traz novas demandas para esses agentes, que lidam com a constante geração, o consumo e a elaboração de informação, um processo contínuo que cria um ciclo virtuoso e fundamental para seu desenvolvimento; ela está dividida em duas vertentes que compõem e mantém seu quadro funcional: a empresa privada e o Estado.

As empresas privadas, de modo geral, buscam estratégias que ampliem suas vantagens competitivas no mercado, estando à procura de informações que as tornem fortes concorrentes em seu setores, ampliem sua gama de consumidores e as tornem mais dinâmicas no desenvolvimento de produtos mais atrativos. O Estado utiliza a informação para manutenção da ordem, pois ele está voltado para a análise da realidade, de modo a responder à sociedade com políticas públicas que garantam seu bem-estar, o desenvolvimento do sujeito e a promoção do exercício da cidadania. Por ter aspecto mais amplo e atender à interesses comuns, vê-se aqui o acesso à informação como uma questão do Estado.

Um cidadão só tem consciência de seus deveres e direitos se tiver acesso a eles enquanto pertencente a uma nação, por isso ele deve estar provido de informação e de instituições públicas que garantam o que lhe é justo. O surgimento de entidades civis, como ONGs e sindicatos, aparecem como um sintoma ou uma resposta à deficiência e negligência do Estado frente à sociedade, que deve promover iniciativas e ações governamentais que combatam o atraso e o isolamento tecnológico e econômico por meio do uso intensivo da informação.

São muitos os desafios que o Estado de uma nação em desenvolvimento enfrenta. No caso particular do Brasil, deficiências de ordem básica, como analfabetismo e probreza, acentuam a corrida contra o crescimento social e, consequentemente, tecnológico. Entretanto, a informação deve ser vista como um recurso de gestão, com políticas próprias que garantam ao cidadão acesso livre a informações públicas, desenvolvimento cultural e participação social. É de responsabilidade do poder 
público promover ao cidadão bases para que ele tenha condições de desempenhar seu papel na sociedade em que vive.

No Brasil, o governo federal, por meio do Conselho Nacional de Ciência e Tecnologia, tem mostrado sua capacidade de reação ao paradigma tecnoinformacional. De acordo com o Programa Sociedade da Informação, idealizado em 1996, pretende-se, por intermédio de serviços de computação, comunicação e informação, estruturar as bases para uma ação de alcance nacional, voltada para a sociedade civil, para a pesquisa, para a educação e para o setor econômico, com o propósito de construir uma sociedade da informação brasileira. (MIRANDA, 2000 apud FERREIRA, 2003 p.38)

O acesso aos meios tecnológicos e à internet é um dos assuntos que deve pautar tais políticas, pois a própria rotina do cidadão já o coloca em contato com as tecnologias de rede e exige dele condições para estar inserido nesta sociedade virtual; essa já é uma necessidade da ordem do dia. Entretanto, nesse caminho, é travado um combate sério entre o analfabetismo e o analfabetismo digital, o que retoma a problemática de acesso à educação básica no país. Uma vez o que sujeito não consegue decifrar os códigos da própria língua, como acessar uma plataforma composta majoritariamente de conteúdos na forma escrita? Seriam várias as possibilidades que orientasse o ensino pelo uso de diversas ferramentas tecnológicas, em que a relação ensino e aprendizagem fosse mais dinâmica, porém, a inclusão deve começar muito antes. Professores também devem estar habilitados a lecionar com ferramentas as quais tenham conhecimento, para as quais foram preparados.

A era da informação é um tempo comum a todos e as tecnologias e soluções digitais estão cada dia mais avançadas, porém, nem todos têm acesso a elas. $\mathrm{O}$ analfabetismo abrange grande parte da população, e não se tem em conta a parcela de analfabetos digitais. As duas falhas de estrutura educacional colocam essas mesmas pessoas num quadro desleal de competitividade, contribuindo, por consequência, no índice de desemprego. O novo contexto de trabalho requer que o trabalhador tenha domínio da linguagem das máquinas, além das habilidades já antes exigidas e da aptidão em aprender. Ou seja, o mundo da tecnologia também deveria ser o 
da inclusão social.

Todo cidadão precisa ter acesso às tecnologias da informação, mas no Brasil, como corrobora a experiência de Baggio (2000) com o Comitê para Democratização da Informática, os projetos sociais são muitas vezes a porta de entrada das pessoas no universo da informática. Porém, embora elas tenham consciência da necessidade de se ter esse tipo de formação como requisito exigido pelo mercado, esse conhecimento não é o suficiente.

O mero acesso ao computador não é em si um exercício de cidadania, e incluir digitalmente não significa diminuir as desigualdades econômicas ou sociais, mas um esforço para que elas não se acentuem. A inclusão deve considerar o processo cognitivo do sujeito, desenvolver sua capacidade de questionamento sobre as possibilidades de uso dessas tecnologias e fortalecer seu papel de cidadão, promovendo autonomia e capacidade de produção de conhecimento, porém, as políticas públicas estão mais voltadas à formação instrumental.

A inclusão social perpassa também o acesso aos equipamentos tecnológicos, o que encontra nova dificuldade no contexto nacional, pois o poder aquisitivo de muitos cidadãos não os permite a compra ou mesmo o uso de computadores, o que torna essa realidade informacional mais distante, pois mesmo quando membros de comunidades em que escolas e bibliotecas públicas possuem recursos computacionais, eles estão excluídos do uso por falta de capacitação. É muito importante haver unidades e sistemas de informação, mas tão importante quanto é haver serviços de habilitação dos usuários.

O crescimento acelerado da internet e sua popularização trouxeram consigo uma quantidade inumerável de informação e de informação duvidosa. Mais que juízo de valores, o que é posto em cheque é o conteúdo dessas informações, sua real contribuição para a formação do indivíduo. Mais uma vez, o Estado deve se fazer presente, com normas para reger o espaço virtual e políticas públicas para proteger o cidadão. Do mesmo modo, os profissionais que atuarão nesse regime devem estar igualmente bem-preparados, uma vez que o processo exigirá práticas de coleta, processamento e disseminação da informação.

\section{Uma questão de poder}


A sociedade é movida por organizações, como empresas e governos, ordenados em formas e estruturas e com objetivos distintos. O poder das empresas, que possuem objetivos específicos e focados, é expresso na manipulação do mercado e na influência política que exercem, pois interferem diretamente na economia, na riqueza das nações. O poder do Estado, cujos objetivos são bastante amplos, pois devem atender os cidadãos, estão vinculados aos interesses sociais e é legitimado por suas ações, expressas na manipulação do sistema. A informação é um produto social, não uma mercadoria, pois ela condiciona a existência da sociedade, entretanto, o desenvolvimento tecnológico é orientado pelo mercado. Manipular a informação é um exercício de controle, e num contexto em que não há controle sobre o que se produz, fica a dúvida se o excesso de informação não teria a intenção de ocultar a informação que de fato interessa.

A internet, ícone da sociedade da informação, é o novo espaço em que os diferentes poderes se manifestam, onde grandes empresas de comunicação lutam para se destacar, bombardeando descontroladamente o ciberespaço com informações, influenciando a opinião pública de acordo com seus interesses e tonando o ambiente caótico. Ela é parte estratégica no processo de posicionamento competitivo, é por onde as mídias se utilizam da comunicação para o condicionamento social, um meio eficaz de manutenção de poder, sem se preocuparem com a ética, pois adaptam seus instrumentos e fontes de persuasão para manterem-se dominantes e colocam os consumidores à frente dos cidadãos.

À parte as questões de liberdade de expressão, nesse contexto se faz necessário uma política que vise o controle do conteúdo que se disponibiliza, uma vigilância saudável em prol da cidadania. Ressalta-se que a liberdade e a informação são essenciais no desenvolvimento do conhecimento, pois ter informação auxilia nas tomadas de decisão e torna possível avaliar algo ao se ter conhecimento sobre ele, mas a garantia de qualidade e segurança devem ser asseguradas por normas governamentais, "é do Estado a responsabilidade de determinar correções em benefícios da sociedade" (SILVEIRA, 2005, p. 05), pois sua grandeza está na administração, no controle que pode exercer sobre as forças globais dos meios de comunicação.

Poder expressar-se configura-se uma forma de fazer com que esses direitos sejam discutidos, significa uma possibilidade de inserção, embora tais formas fragmentadas de luta política pos- 
sam ser questionadas por não visar a mudança estrutural da sociedade, mas a inserção de determinados grupos nos setores privilegiados da mesma. (CARVALHO, 2009, p. 21).

O cidadão deve ter voz, para não ser dominado por quaisquer tipos de poder, seja do meio privado ou do público; ele não pode ser boicotado pela desinformação, pela falta de quantidade e qualidade de informação. Ao mesmo tempo que as tecnologias podem servir de instrumento de controle sobre a sociedade, os novos recursos informacionais devem servir igualmente para que o povo exerça seus direitos - senão poderes - sobre os governantes, pois a relação entre sociedade e Estado se transforma quando o sujeito conquista o direito de participar da reelaboração do sistema.

\section{Considerações finais}

As transformações sociais foram e ainda são fortemente impactadas pelas redes de comunicação, e as tecnologias são um produto cultural da sociedade, objeto de manipulação, desenvolvimento e transformação em prol do bem-estar; atualmente, a internet é a maior responsável pelas relações e transposições de barreiras, inclusive geográficas.

A valorização da informação e a diversidade de recursos informacionais disponibilizados em diversos ambientes, principalmente no digital, dificultam sua busca, localização e acesso. A Web Semântica surge no contexto da Ciência da Informação com o propósito de proporcionar a estrutura necessária para uma melhor representação e recuperação dessa informação, criando, deste modo, uma rede de conhecimento. Seu potencial está na troca e processamento de informações disponibilizadas nos diversos ambientes informacionais, de modo que pessoas e computadores trabalhem em cooperação.

A Sociedade da Informação é um desafio para o Estado, principalmente no que tange à criação de normas de segurança e acesso à informação e o trabalho de inclusão social do indivíduo no universo digital. A problemática se estabelece desde o déficit de formação básica do cidadão, que só se agrava com o desenvolvimento e descompasso tecnológico nacional. Logo, essa nova ordem informacional exige que o Estado repense sua legislação e suas políticas públicas, principalmente 
a educacional, pois ele deve promover o desenvolvimento intelectual e cultural do cidadão, podendo, para isso, ter na tecnologia um aparato que auxilie no diálogo entre prática e teoria.

Ampliar o acesso à informação é investir no bem-estar e na qualidade de vida, é promover uma sociedade mais inclusiva e igualitária. O Brasil precisa adotar políticas que contemplem não apenas as falhas no acesso à informação, mas também as falhas no processo de entendimento e assimilação da informação, ou seja, do processo educacional, gerando inclusão social, não desigualdade pela concorrência desleal de oportunidades.

As tecnologias da informação, em especial a internet, vêm promovendo mudanças significativas na sociedade, alterando seu comportamento, demandas e necessidades, transformação que a Web trilhou de forma bastante semelhante, uma vez que se desenvolveu e foi incorporada de maneira natural pelos usuários, com atores e linguagens específicas para compor sua estruturação.

\section{Referências}

ALVES, Rachel Cristina Vesú; SANTOS, Plácida Leopoldina Ventura Amorim da Costa. Metadados e Web Semântica para estruturação da Web 2.0 e Web 3.0. DataGramaZero: Revista de Ciência da Informação, Rio de Janeiro, v. 10, n. 6, dez. 2009. Disponível em: <http://periodicos.ufpb.br/ojs/index.php/pbcib/article/view/10406>. Acesso em: 12 jan. 2016

BAGGIO, Rodrigo. A sociedade da informação e a infoexclusão. Ci. Inf., Brasília, v. 29, n. 2, p. 16-21, maio/ago. 2000. Disponível em: <http://www.scielo.br/pdf/ci/v29n2/a03v29n2.pdf>. Acesso em: 10 jan. 2016

CARVALHO, Olívia Bandeira de Melo. Os "incluídos digitais"são"incluídos sociais"? Estado, mercado e inserção dos indivíduos na sociedade da informação. Liinc em Revista, Rio de Janeiro, v. 5, n. 1, p. 19-31, mar. 2009. Disponível em: <revista.ibict.br/liinc/index.php/liinc/article/viewFile/294/184 >. Acesso em: 12 jan. 2016

FERREIRA, Rubens da Silva. A sociedade da informação no Brasil: um ensaio sobre os desafios do Estado. Ci. Inf., Brasília, v. 32, n. 1, p. 36-41, jan./abr. 2003. Disponível em: <http://portal.iadebrasil.com.br/pos/biblioteca/ alfabetizacao-letramento/modulol/pdf/8\%20A\%20sociedade\%20da\%20informa\%C3\%A7\%C3\%A30\%20no\%20 Brasil.pdf>. Acesso em: 15 fev. 2016 
MUCHERONI, Marcos Luiz; PALETTA, Francisco Carlos. O desenvolvimento da Web 3.0: Linked Data e DBPEDIA.

Prisma.Com, Porto, n. 25, p. 73-90, 2014. Disponível em: <http://revistas.ua.pt/index.php/prismacom/article/ view/3047>. Acesso em: 16 fev. 2016

NICOLAU, Marcos; SANTOS, Emanuella. Web do futuro: a cibercultura e os caminhos trilhados rumo a uma Web semântica ou Web 3.0. Revista Temática, ano 8, n. 10, out. 2012. Disponível em: <http://periodicos.ufpb.br/ index.php/tematica/issue/view/1508>. Acesso em: 10 jan. 2016.

SILVEIRA, Henrique Flávio Rodrigues da. Um estudo do poder na sociedade da informação. Ci. Inf., Brasília, v. 29, n. 3, p. 79-90, set./dez. 2000. Disponível em: <http://www.scielo.br/pdf/ci/v29n3/a08v29n3.pdf>. Acesso em: 12 jan. 2016 